- Erratum

\title{
Erratum: The Relationship between Dog Ownership and Physical Activity in Korean Adults
}

\author{
Miso Park, Hoon-Ki Park*, Hwan-Sik Hwang, Kye-Yeung Park, Ho-Hyoun Yim \\ Department of Family Medicine, Hanyang University College of Medicine, Seoul, Korea
}

https://doi.org/10.4082/kjfm.19.0143

Korean J Fam Med 2021;42:59-65

There was an error in the article, "The relationship between dog ownership and physical activity in Korean adults [1]." In the References list, two references were overlapped at No. 10, and then the reference numbers were incorrectly assigned. The list of correct references has been modified as follows:

10. de Rezende LF, Rey-Lopez JP, Matsudo VK, do Carmo Luiz O. Sedentary behavior and health outcomes among older adults: a systematic review. BMC Public Health 2014;14:333.

11. Health Insurance Review and Assessment Service. Public major disease statistics [Internet]. Wonju: Health Insurance Review and Assessment Service; 2020 [cited 2019 Aug 15]. Available from: http://opendata.hira.or.kr/op/opc/olapMfrnIntrsIlnsInfo.do.

12. Ministry of Culture, Sports and Tourism. 2018 Public leisure activity survey report. Sejong: Ministry of Culture, Sports and Tourism; 2018.

13. Anderson WP, Reid CM, Jennings GL. Pet ownership and risk factors for cardiovascular disease. Med J Aust 1992;157:298-301.

14. Soares J, Epping JN, Owens CJ, Brown DR, Lankford TJ, Simoes EJ, et al. Odds of getting adequate physical activity by dog walking. J Phys Act Health 2015;12 Suppl 1:S102-9.

15. Oka K, Shibata A. Dog ownership and health-related physical activity among Japanese adults. J Phys Act Health 2009;6:412-8.

16. Westgarth C, Christley RM, Jewell C, German AJ, Boddy LM, Christian HE. Dog owners are more likely to meet physical activity guidelines than people without a dog: an investigation of the association between dog ownership and physical activity levels in a UK community. Sci Rep 2019;9:5704.

17. Reeves MJ, Rafferty AP, Miller CE, Lyon-Callo SK. The impact of dog walking on leisure-time physical activity: results from a populationbased survey of Michigan adults. J Phys Act Health 2011;8:436-44.

18. Brown SG, Rhodes RE. Relationships among dog ownership and leisure-time walking in Western Canadian adults. Am J Prev Med 2006;30:131-6.

19. Yabroff KR, Troiano RP, Berrigan D. Walking the dog: is pet ownership associated with physical activity in California? J Phys Act Health 2008;5:216-28.

20. Schofield G, Mummery K, Steele R. Dog ownership and human health-related physical activity: an epidemiological study. Health Promot J Austr 2005;16:15-9 
We sincerely apologized to the readers.

\section{REFERENCE}

1. Park M, Park HK, Hwang HS, Park KY, Yim HH. The relationship between dog ownership and physical activity in Korean adults. Korean J Fam Med 2021;42:59-65. 